\title{
Calcium supplementation after parathyroidectomy in dialysis and renal transplant patients
}

This article was published in the following Dove Press journal: International Journal of Nephrology and Renovascular Disease 14 May 2014

Number of times this article has been viewed

\author{
Marius C Florescu' \\ KM Monirul Islam² \\ Troy J Plumb' \\ Sara Smith-Shull ${ }^{3}$ \\ Jennifer Nieman ${ }^{3}$ \\ Prasanti Mandalapu' \\ 'Nephrology Department, ${ }^{2}$ Institute \\ of Public Health, ${ }^{3}$ Department of \\ Pharmacy, The Nebraska Medical \\ Center, Omaha, NE, USA
}

Correspondence: Marius C Florescu 983040 Nebraska Medical Center, Omaha, NE 69198-3040, USA

Tel +l 4025599227

Fax +l 4025599504

Email mflorescu@unmc.edu
Background: Data on the risk factors and clinical course of hungry bone syndrome are lacking in dialysis and renal transplant patients who undergo parathyroidectomy. In this study, we aimed to assess the risks and clinical course of hungry bone syndrome and calcium repletion after parathyroidectomy in dialysis and renal transplant patients.

Methods: We performed a retrospective review of parathyroidectomies performed at The Nebraska Medical Center.

Results: We identified 41 patients, ie, 30 (73\%) dialysis and eleven (27\%) renal transplant patients. Dialysis patients had a significantly higher pre-surgery intact parathyroid hormone (iPTH, $P<0.001)$ and a larger iPTH drop after surgery $(P<0.001)$ than transplant recipients. Post-surgery hypocalcemia in dialysis patients was severe and required aggressive and prolonged calcium replacement $(11 \mathrm{~g})$ versus a very mild hypocalcemia requiring only brief and minimal replacement $(0.5 \mathrm{~g})$ in transplant recipients $(P<0.001)$. Hypophosphatemia was not detected in the dialysis group. Phosphorus did not increase immediately after surgery in transplant recipients. The hospital stay was significantly longer in dialysis patients ( 8.2 days) compared with transplant recipients (3.2 days, $P<0.001)$.

Conclusion: The clinical course of hungry bone syndrome is more severe in dialysis patients than in renal transplant recipients. Young age, elevated alkaline phosphatase, elevated presurgery iPTH, and a large decrease in post-surgical iPTH are risk factors for severe hungry bone syndrome in dialysis patients.

Keywords: parathyroidectomy, hungry bone syndrome, hypocalcemia

\section{Introduction}

Secondary hyperparathyroidism is a common complication of end-stage renal disease (ESRD). Despite appropriate treatment, 50\% of ESRD patients have parathyroid hormone (PTH) levels more than three times the normal value. ${ }^{1}$ Hyperparathyroidism with the associated hyperphosphatemia and elevated calcium $\times$ phosphorus product have been associated with increased mortality, increased cardiovascular morbidity, and uremic bone disease in the ESRD population. ${ }^{2}$

Vitamin D3 deficiency, increased fibroblast growth factor 23, and abnormalities of calcium-phosphorus metabolism induced by the progressive decline in renal function are considered the main factors in the pathogenesis of secondary hyperparathyroidism. ${ }^{3}$ Initially, the uremic milieu causes a diffuse hyperplasia of the parathyroid glands, which is the pathologic lesion found in secondary hyperparathyroidism. This diffuse proliferation of parathyroid cells is relatively slow-growing and is associated with decreased concentrations of calcium sensing receptors and vitamin D receptors compared with 
normal parathyroid tissue, but is still responsive to medical therapy. Without optimal treatment, diffuse hyperplasia progresses to nodular hyperplasia, the pathologic counterpart of refractory secondary hyperparathyroidism. In nodular hyperplasia, the parathyroid gland contains nodules of rapidly proliferating parathyroid cells. Each nodule, formed by monoclonal proliferation of parathyroid cells, is producing excessive amounts of PTH. Because of the low density of calcium sensing receptors and vitamin D receptors, these cells are refractory to medical treatment (activated vitamin D, calcimimetics, control of hyperphosphatemia). ${ }^{4-6}$ Parathyroidectomy with reimplantation of parathyroid tissue is the treatment of choice for refractory secondary hyperparathyroidism. All the patients (dialysis and renal transplant) included in our study had secondary refractory hyperparathyroidism.

Renal transplantation is not followed by resolution of secondary hyperparathyroidism in all patients. Despite adequate renal function, $25 \%$ of patients still have elevated PTH levels one year post-transplantation. ${ }^{7}$ Tubulointerstitial calcifications were described in early protocol renal biopsies for patients with persistent hyperparathyroidism and hypercalcemia, and were associated with inferior graft outcomes one year post-transplantation. ${ }^{8}$ Hyperparathyroidism and hypercalcemia can promote vascular calcifications that are associated with increased post-transplant morbidity and mortality. ${ }^{9}$ For these reasons, parathyroidectomy is performed in renal transplant patients. Although slightly increasing the 30-day mortality, parathyroidectomy is associated with a $10 \%-15 \%$ lower long-term mortality in the ESRD population compared with ESRD patients who do not undergo surgery. ${ }^{10,11}$ The incidence of reoperation for moderate to severe recurrent hyperparathyroidism is $6 \%-14 \%{ }^{12}$

A common complication of parathyroidectomy is "hungry bone syndrome", manifested as severe and persistent hypocalcemia. There are no well-defined criteria for diagnosis of hungry bone syndrome. A large study of 198 patients undergoing parathyroidectomy for primary hyperparathyroidism defined hungry bone syndrome as a serum calcium concentration $<8.5 \mathrm{mg} / \mathrm{dL}$ and a serum phosphate concentration $<3 \mathrm{mg} / \mathrm{dL} 3$ days post-surgery. ${ }^{13}$ Jofré et a ${ }^{14}$ reported a $20 \%$ incidence of hungry bone syndrome after parathyroidectomy for secondary hyperparathyroidism in dialysis patients. They defined hungry bone syndrome as total calcium $<8 \mathrm{mg} /$ $\mathrm{dL}$ despite adequate intravenous and oral calcium and calcitriol therapy. The abrupt drop in PTH after parathyroidectomy is believed to modify the balance between bone formation and bone resorption, favoring bone formation with net bone uptake of calcium, phosphorus, and magnesium, leading to severe hypocalcemia. The lack of well-defined criteria for the diagnosis of hungry bone syndrome makes the study of this condition more challenging.

Despite current advances in our understanding of the pathophysiology of secondary hyperparathyroidism, there is a lack of data regarding the hungry bone syndrome that develops after parathyroidectomy in dialysis and renal transplant patients. The aim of this study was to gain an insight into aspects of hungry bone syndrome that had not been previously analyzed. We attempted to establish: the predictors of developing severe hypocalcemia; the amount of calcium supplementation needed; how long patients need to be admitted for to maintain a safe calcium level; the number of postsurgical days requiring more calcium supplementation; whether hungry bone syndrome in the renal transplant population is as severe as that in dialysis patients; if hypophosphatemia is present; and whether there is any need for phosphate replacement.

\section{Materials and methods}

We undertook a retrospective chart review of all patients with ESRD and renal transplantation who underwent parathyroidectomy for refractory secondary hyperparathyroidism at The Nebraska Medical Center, Omaha, NE, USA, between January 2000 and December 2007. Indications for surgery in ESRD patients consisted of markedly elevated and nonsuppressible serum intact PTH (iPTH) despite appropriate medical therapy associated with symptoms attributable to secondary hyperparathyroidism. Indications for parathyroidectomy in the renal transplant group were persistently elevated PTH levels and hypercalcemia. All the surgeries were performed at our institution. The transplant patients had a mean of 2.5 (range 1-3.5) glands removed and no autotransplantation, while the hemodialysis patients had a mean of 3.0 (range 1-4) glands removed and 13 of 30 had one gland autotransplanted. The patient's electronic medical record and pharmacy records were reviewed. We recorded demographic data, comorbid conditions, time on dialysis (dialysis group) or creatinine before surgery (transplant group), pre-surgery serum iPTH, calcium, phosphorus, albumin, creatinine, surgical procedure performed (including the main operator), gland reimplantation, pathological evaluation of the parathyroid glands, number of glands and their weight, postoperative PTH, post-surgery calcium, phosphorus, calcium repletion (including oral and intravenous during the entire hospital admission that was converted for our analysis into elemental calcium), use of vitamin D products, calcium baths used in hemodialysis, and duration of hospitalization. Calcium and 
phosphorus were checked several times a day. Large doses of oral calcium given 2 hours after meals and calcitriol were started immediately after surgery and intravenous calcium was used to treat severe hypocalcemia. Dialysis patients received high calcium bath dialysis. Phosphorus binders were not given. For each hospital day, we recorded mean serum calcium and phosphorus levels.

\section{Definitions}

In an attempt to identify predictors of severe hungry bone syndrome in dialysis patients, we defined severe hungry bone syndrome as the need for $>11 \mathrm{~g}$ of oral and intravenous elemental calcium replacement during the hospital admission, $>8$ days of hospitalization, and lowest calcium recorded at $<7 \mathrm{mg} / \mathrm{dL}$. We chose these values as being above the mean values for these three parameters. To calculate the elemental calcium administered, we used the following: $90 \mathrm{mg}$ of elemental calcium contained in 1,000 mg of calcium gluconate, $270 \mathrm{mg}$ of elemental calcium in $1,000 \mathrm{mg}$ of calcium chloride, $169 \mathrm{mg}$ of elemental calcium in $667 \mathrm{mg}$ of calcium acetate, and $400 \mathrm{mg}$ of elemental calcium in $1,000 \mathrm{mg}$ of calcium carbonate.

\section{Assays}

Total serum calcium (normal range $8.9-10.3 \mathrm{mg} / \mathrm{dL}$ ), serum phosphate $(2.4-4.7 \mathrm{mg} / \mathrm{dL})$, iPTH $(12-88 \mathrm{pg} / \mathrm{mL})$, serum albumin $(3.4-4.7 \mathrm{~g} / \mathrm{dL})$, serum creatinine $(0.44-1.03 \mathrm{mg} / \mathrm{dL})$, and serum alkaline phosphatase (31-91 U/L) were measured. All calcium values were recorded as total serum calcium measured in $\mathrm{mg} / \mathrm{dL}$ and the values were corrected for the decrease in serum albumin by adding $0.8 \mathrm{mg} / \mathrm{dL}$ to the calcium value for each $1 \mathrm{~g} / \mathrm{dL}$ decrease in serum albumin below $4 \mathrm{~g} / \mathrm{dL}$.

\section{Statistical analysis}

Descriptive statistics were used to describe the study populations. Comparison of means for the two groups was done using the Student's $t$-test with the pooled variance estimate when the group variances could be assumed to be equal. Comparisons of means when the two variances should not be considered equal were analyzed with an unequal variance model. Both types of tests were computed with PROC MIXED (SAS Institute, Cary, NC, USA). For most variables, plots of the data indicated no severe outliers or serious departure from normality. The three variables corresponding to the amount of calcium received showed some outliers and an undesirably large number of zeros, so a nonparametric Wilcoxon test was run to test for equality of medians with PROC NPAR1WAY (SAS Institute). Duration of hospital stay was analyzed using the log-rank test from PROC LIFEREG (SAS Institute). We used multivariate regression analysis to identify predictors of severe hungry bone syndrome in dialysis patients after assessing the relationships of individual variables with the outcome.

\section{Results}

\section{Study population}

Forty-one patients were identified, comprising 30 (73\%) on dialysis and $11(27 \%)$ with a functioning renal allograft. The mean age was 47.5 years in the dialysis group and 52.0 years in the transplant group. The mean time spent on dialysis in the dialysis group was 6.26 years. The mean serum creatinine in the transplant group was $1.7 \mathrm{mg} / \mathrm{dL}$. The mean time from renal transplantation to parathyroidectomy was 5.3 years. Table 1 shows the study population.

\section{Calcium and iPTH}

In the dialysis group, 26 of 30 patients (86.6\%) had postoperative serum calcium $<8 \mathrm{mg} / \mathrm{dL}$ despite aggressive calcium replacement. In contrast, only three of eleven patients (27.3\%) in the transplant group had a serum calcium $<8 \mathrm{mg} / \mathrm{dL}$. In the dialysis group, 26 patients $(86.6 \%)$ required intravenous calcium versus four of eleven (36.3\%) in the transplant group. Table 2 presents the major findings of this analysis.

The pre-surgery iPTH was significantly higher in the dialysis group than in the transplant group, as seen in Figure 1. The post-surgery iPTH decline was higher in the dialysis group than in the transplant group. The pre-surgery corrected total serum calcium was higher in the transplant group. The post-surgical decrease in serum calcium was higher in the dialysis group than in the transplant group $(1.86 \mathrm{mg} / \mathrm{dL}$ versus $1.5 \mathrm{mg} / \mathrm{dL})$. In the dialysis patients, the post-surgery decrease in serum calcium was limited by

Table I Description of the study population

\begin{tabular}{ll}
\hline Patients (n) & 4 I \\
Dialysis & 30 (I6 men, \\
& I4 women) \\
Renal transplant & II (5 men, 6 women) \\
Mean (SD) patient age (years) & \\
$\quad$ Dialysis & $47.5 \pm 16.14$ \\
Transplant & $52.0 \pm 7.33$ \\
Mean duration of ESRD (years) in dialysis patients & $6.26 \pm 4.75$ \\
$\begin{array}{l}\text { Mean (SD) serum creatinine level at surgery } \\
\text { for transplant patients }\end{array}$ & $1.74 \pm 0.67 \mathrm{mg} / \mathrm{dL}$ \\
Mean time to parathyroidectomy after & 5.3 \\
renal transplantation (years) & \\
\hline
\end{tabular}

Abbreviations: SD, standard deviation; ESRD, end-stage renal disease. 
Table 2 Comparison of different variables between dialysis patients and transplant recipients

\begin{tabular}{|c|c|c|c|}
\hline Variables & $\begin{array}{l}\text { Dialysis } \\
\text { group }\end{array}$ & $\begin{array}{l}\text { Transplant } \\
\text { group }\end{array}$ & $P$-value \\
\hline Pre-surgery mean iPTH (ng/L) & $2,042.1$ & 261.7 & $<0.001$ \\
\hline Post-surgery mean iPTH (ng/L) & 289.9 & 114.7 & 0.21 \\
\hline $\begin{array}{l}\text { Post-surgery decrease } \\
\text { in } \mathrm{PTTH}(\mathrm{ng} / \mathrm{L})\end{array}$ & $\mathrm{I}, 752$ & 147 & $<0.001$ \\
\hline $\begin{array}{l}\text { Pre-surgery corrected } \\
\mathrm{tCa}(\mathrm{mg} / \mathrm{dL})\end{array}$ & 9.70 & 10.51 & 0.035 \\
\hline $\begin{array}{l}\text { Post-surgery corrected tCa } \\
\text { at day I (mg/dL) }\end{array}$ & 7.96 & 9.01 & 0.003 \\
\hline $\begin{array}{l}\text { Post-surgery decrease } \\
\text { of serum } \mathrm{tCa}(\mathrm{mg} / \mathrm{dL})\end{array}$ & 1.86 & 1.50 & 0.44 \\
\hline $\begin{array}{l}\text { Mean lowest corrected } \\
\mathrm{tCa}(\mathrm{mg} / \mathrm{dL})\end{array}$ & 6.98 & 8.60 & $<0.001$ \\
\hline $\begin{array}{l}\text { Pre-surgery serum } \\
\text { phosphorus (mg/dL) }\end{array}$ & 6.27 & 3.61 & $<0.001$ \\
\hline Post-surgery phosphorus (mg/dL) & 5.63 & 3.58 & $<0.001$ \\
\hline $\begin{array}{l}\text { Post-surgery decrease } \\
\text { in phosphorus (mg/dL) }\end{array}$ & 0.46 & 0.13 & 0.473 \\
\hline $\begin{array}{l}\text { Mean IV elemental Ca during } \\
\text { admission per patient }(\mathrm{g})\end{array}$ & 2.48 & 0.16 & 0.0017 \\
\hline $\begin{array}{l}\text { Mean oral elemental Ca during } \\
\text { admission per patient ( } \mathrm{g} \text { ) }\end{array}$ & 8.67 & 0.38 & $<0.001$ \\
\hline $\begin{array}{l}\text { Mean IV and oral elemental } \mathrm{Ca} \\
\text { during admission per patient ( } \mathrm{g} \text { ) }\end{array}$ & 11.15 & 0.55 & $<0.001$ \\
\hline Gland weight (g) & $1.5 \mathrm{I}$ & 0.99 & 0.194 \\
\hline Length of admission (days) & 8.2 & 3.18 & $<0.001$ \\
\hline
\end{tabular}

Abbreviations: iPTH, intact parathyroid hormone; $\mathrm{tCa}$, total calcium; $\mathrm{Ca}$, calcium; IV, intravenous. aggressive calcium repletion. The mean lowest recorded calcium value was significantly lower in the dialysis group than in the transplant group despite the dialysis group receiving much larger doses of intravenous and oral calcium and $3.5 \mathrm{mEq} / \mathrm{L}$ calcium bath hemodialysis treatments.

The calcium requirements between the groups were very different. As presented in Figure 2, the amounts of intravenous and oral elemental calcium required to treat hypocalcemia were much higher in the dialysis group than in the transplant group. The transplant group required roughly $0.5 \mathrm{~g}$ of elemental calcium during the entire admission versus dialysis patients requiring on average $11 \mathrm{~g}$ of elemental calcium.

\section{Phosphorus}

As expected, serum phosphorus was higher in the dialysis group than in the transplant group. The postoperative decrease in phosphorus was minimal in both groups $(0.46 \mathrm{mg} / \mathrm{dL}$ in the dialysis group and $0.13 \mathrm{mg} / \mathrm{dL}$ in the transplant group) despite successful parathyroidectomy. No patient became hypophosphatemic and no patient received phosphate repletion.

\section{Duration of hospital stay}

The length of admission was significantly longer in the dialysis group compared with the transplant group (Figure 3),

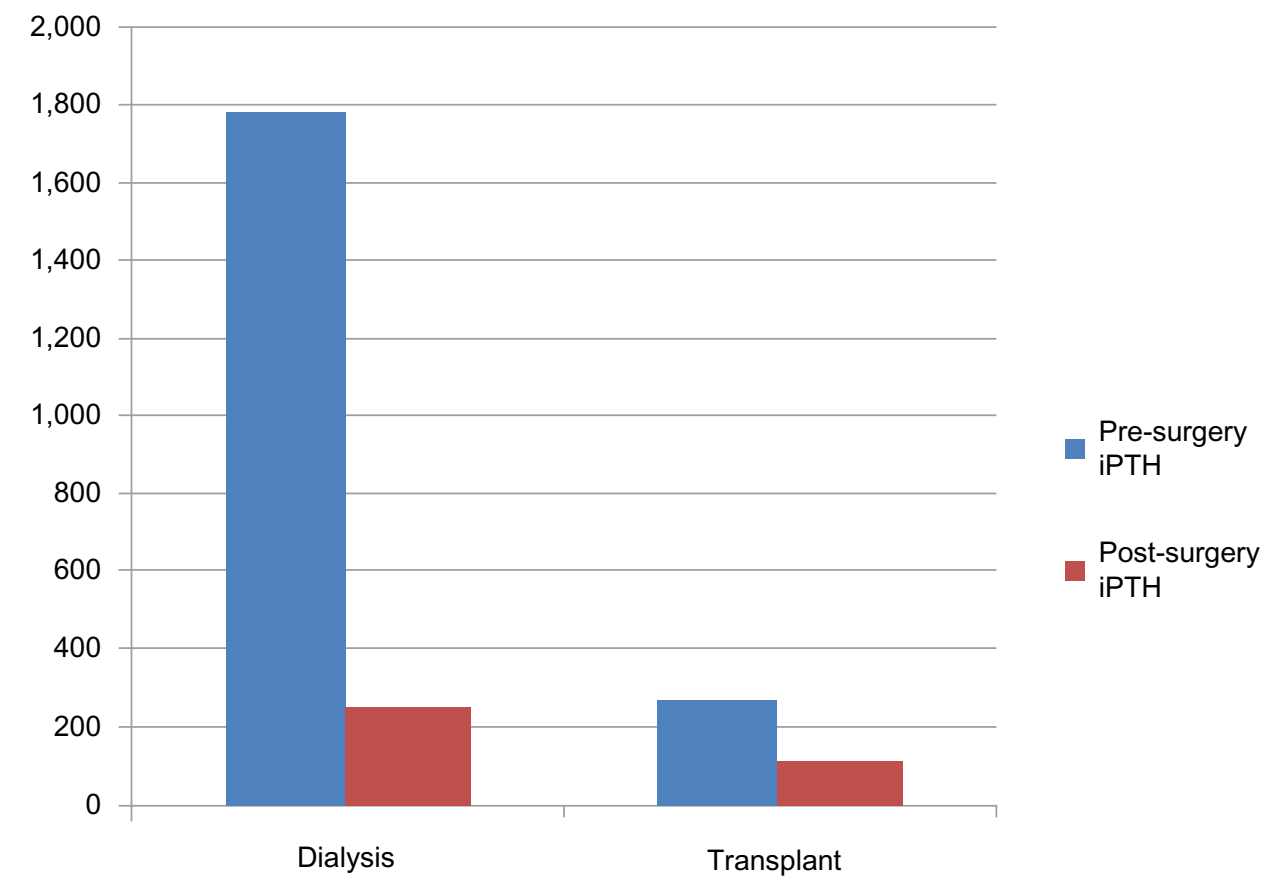

Figure I Mean iPTH (ng/L) levels before and after surgery in dialysis and transplant groups.

Abbreviation: iPTH, intact parathyroid hormone. 


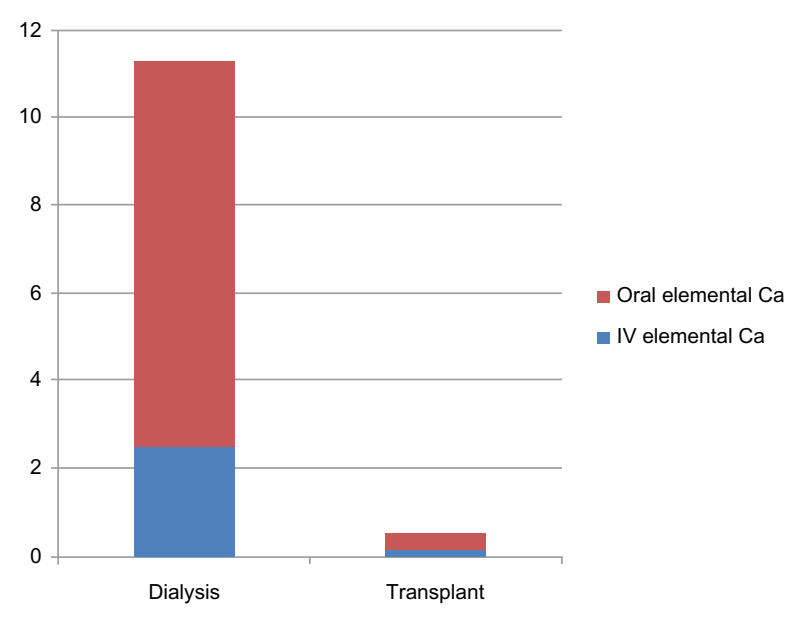

Figure 2 Comparison between dialysis and transplant patients of mean oral and intravenous elemental calcium $(\mathrm{g})$ administered after parathyroidectomy per patient during hospital admission $(P<0.00 \mathrm{I})$.

Abbreviations: IV, intravenous; $\mathrm{Ca}$, calcium

reflecting the need for more intensive calcium monitoring and supplementation in the dialysis group.

\section{Univariate and multivariate analysis}

The results of univariate analysis using Spearman correlation to identify predictors of severe hungry bone syndrome in dialysis patients are presented in Table 3. Multivariate regression analysis of predictors of longer than 8 days admission found that a higher removed gland weight correlated with longer length of hospitalization ( $95 \%$ confidence interval [CI] 0.07-1.5526; $P=0.0308$ ) and elevated alkaline phosphatase showed a trend toward significant correlation ( $95 \%$ CI -0.0002 to 0.0092 ; $P=0.0628$ ) for the same outcome. Multivariate analysis of

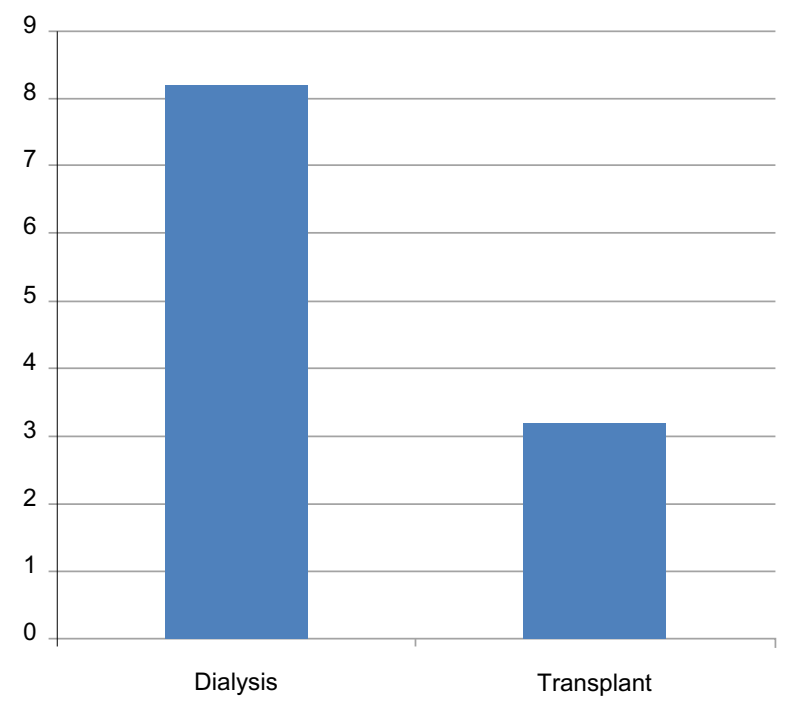

Figure 3 Comparison of length of admission (days) between dialysis and transplant patients $(P<0.001)$. predictors for calcium replacement showed that younger age was significantly correlated with larger calcium replacement (95\% CI -0.3208 to $-0.0366 ; P=0.0137$ ) while elevated alkaline phosphatase was again close to statistical significance (95\% CO -0.0001 to $0.0228 ; P=0.0529)$ for the same outcome. Multivariate analysis for predictors of lowest recorded calcium value showed that younger age correlated with lower calcium values (95\% CI $0.0102-0.0607 ; P=0.0059)$, while elevated alkaline phosphatase ( $95 \% \mathrm{CI}-0.0034$ to $0.0000 ; P=0.0550)$ showed a trend towards the same outcome.

\section{Discussion}

We found significant differences in iPTH levels between dialysis and transplant patients. The pre-surgery serum iPTH levels were much higher in dialysis patients $(2,042.1 \mathrm{ng} / \mathrm{L})$ than in transplant patients $(261.7 \mathrm{ng} / \mathrm{L})$. We have to highlight that the hyperparathyroidism was relatively mild in the transplant group, with iPTH levels below $300 \mathrm{ng} / \mathrm{L}$, close to the results presented by Evenepoel et al, ${ }^{7}$ ie, $107 \mathrm{pg} / \mathrm{mL}$ $(107 \mathrm{ng} / \mathrm{L})$. This reflects a tendency toward resolution of the hyperparathyroidism, with a gradual decrease in iPTH after renal transplantation. Despite adequate post-transplant renal function, $25 \%$ of patients still have elevated PTH levels one year post-transplantation. ${ }^{7}$ In most patients, the plasma iPTH will gradually return to normal after successful renal transplantation, but there will be patients who fail to do so. ${ }^{15}$ The risk of post-transplant persistence of secondary hyperparathyroidism increases with the duration of dialysis ${ }^{16,17}$ and with the severity of pre-transplant hyperparathyroidism. ${ }^{17,18}$ The ability of hyperparathyroidism to spontaneously resolve after restoration of renal function is believed to be determined by the degree of parathyroid hyperplasia. ${ }^{19}$ Patients with persistent posttransplant hyperparathyroidism requiring parathyroidectomy are those who developed nodular hyperplasia and secondary refractory hyperparathyroidism prior to transplantation. ${ }^{20}$

After parathyroidectomy, the iPTH decreased by $1,752 \mathrm{ng} / \mathrm{L}$ in dialysis patients versus only $147 \mathrm{ng} / \mathrm{L}$ in the transplant group. The post-surgery mean iPTH was higher in the dialysis patients than in the transplant patients, probably reflecting the pre-surgery levels.

As expected, the transplant patients were hypercalcemic before surgery. The postoperative calcium drop was $1.86 \mathrm{mg} / \mathrm{dL}$ in the dialysis group and $1.5 \mathrm{mg} / \mathrm{dL}$ in the transplant group. This moderate decrease in calcium should not be misleading. The postoperative drop in calcium was prevented in the dialysis group by frequent monitoring of calcium levels and aggressive repletion using massive doses 
Table 3 Spearman correlation of predictors of severe hungry bone syndrome

\begin{tabular}{|c|c|c|c|c|c|c|}
\hline & \multicolumn{2}{|l|}{ Lowest Ca level } & \multicolumn{2}{|l|}{ Ca replacement } & \multicolumn{2}{|l|}{ Length of hospitalization } \\
\hline & Correlation coefficient & $P$-value & Correlation coefficient & $P$-value & Correlation coefficient & $P$-value \\
\hline Duration of ESRD & -0.243 & 0.24 & 0.022 & 0.92 & -0.09 & 0.67 \\
\hline Pre-surgery iPTH & -0.640 & 0.002 & 0.583 & 0.006 & 0.192 & 0.40 \\
\hline Post-surgery iPTH & -0.521 & 0.032 & 0.579 & 0.015 & 0.414 & 0.10 \\
\hline Change in iPTH & -0.596 & 0.019 & 0.396 & 0.14 & 0.013 & 0.96 \\
\hline Age & 0.608 & $<0.001$ & -0.583 & $<0.001$ & -0.171 & 0.37 \\
\hline Gland weight & 0.186 & 0.36 & 0.061 & 0.77 & 0.408 & 0.038 \\
\hline Alkaline phosphatase & -0.586 & 0.003 & 0.540 & 0.006 & 0.436 & 0.033 \\
\hline
\end{tabular}

Abbreviations: $\mathrm{Ca}$, calcium; ESRD, end-stage renal disease; iPTH, intact parathyroid hormone.

of intravenous and oral calcium. During the entire admission, dialysis patients received on average $11.15 \mathrm{~g}$ of elemental calcium versus $0.55 \mathrm{~g}$ for the transplant patients.

The mean lowest serum calcium recorded was significantly lower in the dialysis patients $(6.98 \mathrm{mg} / \mathrm{dL})$ than in the transplant recipients $(8.60 \mathrm{mg} / \mathrm{dL})$, despite dialysis patients receiving on average 20 times more elemental calcium. This highlights the need for frequent calcium monitoring especially in dialysis patients, because the calcium can decrease rapidly and needs prompt replacement to avoid severe hypocalcemia.

Further supporting the important differences between the groups in the severity of the hungry bone syndrome, in the dialysis group $86.6 \%$ had postoperative serum calcium $<8 \mathrm{mg} / \mathrm{dL}$ despite aggressive calcium replacement compared with only $27.3 \%$ in the transplant group. Further, in the dialysis group, $86.6 \%$ required intravenous calcium versus only $36.3 \%$ in the transplant group. With careful monitoring and aggressive calcium repletion we did not record any complication attributable to severe hypocalcemia.

The length of admission was dictated by the need for intravenous calcium replacement and less by post-surgical recovery. The mean duration of admission was 8.2 days for dialysis patients. In contrast, the transplant patients could be discharged after 3.18 days on average.

In contrast with the dialysis patients, the transplant patients did not develop hungry bone syndrome. Their preoperative calcium was higher and decreased to levels just below the normal limit. The need for calcium supplementation in the transplant patients was minimal and they could be safely discharged home after a short hospital stay.

The large differences in the severity of hungry bone syndrome we found might be related to pre-surgery iPTH levels. Pre-surgery iPTH was very elevated in the dialysis patients and only mildly elevated in the transplant patients. Consequently, after parathyroidectomy, the mean iPTH drop was more than ten times higher in the dialysis patients than in transplant patients. This suggests that the pre-parathyroidectomy iPTH level and/or the magnitude of postoperative iPTH drop might correlate with the severity of hungry bone syndrome following surgery.

Prior to surgery, phosphorus was elevated in the dialysis group and within normal limits in the transplant group. After parathyroidectomy, serum phosphorus decreased by $0.46 \mathrm{mg} / \mathrm{dL}$ in the dialysis group and by $0.13 \mathrm{mg} / \mathrm{dL}$ in the transplant patients. No patient became hypophosphatemic and none required phosphorus supplementation in either group. This is surprising. In ESRD patients, we currently consider that post-parathyroidectomy hypocalcemia is caused by an acute decrease in bone resorption and persistence of rapid bone formation which consumes large amounts of calcium. However, creation of new bone also requires large amounts of phosphorus, and a major drop in phosphorus was not seen. The explanation for this is unclear. We can hypothesize that the phosphorus needed for bone formation in ESRD patients is more easily available from other sites in the body and severe hypophosphatemia is averted. Compared with calcium, that is $99.9 \%$ stored in the bones, $7 \%$ of body phosphorus is located intracellularly and $93 \%$ in the bone. ${ }^{21}$ The intracellular compartment might supply the phosphorus needed for bone formation. Further, in order to produce the main bone mineral, ie, hydroxyapatite $\left[\mathrm{Ca}_{10}\right.$ $\left.\left(\mathrm{PO}_{4}\right)_{6}(\mathrm{OH})_{2}\right]$, the amount of phosphorus needed to match the calcium used is roughly half (for each $1,000 \mathrm{mg}$ of calcium, $465 \mathrm{mg}$ of phosphorus is needed) and the lower phosphorus requirement dampens the magnitude of the decrease in serum phosphorus. Transplant patients were not hypophosphatemic despite their elevated iPTH and relatively preserved renal function (mean creatinine $1.74 \mathrm{mg} / \mathrm{dL}$ ). In the transplant group, serum phosphorus decreased by $0.13 \mathrm{mg} / \mathrm{dL}$ immediately post-parathyroidectomy. This decrease is surprising. In their series, Evenepoel et $\mathrm{al}^{7}$ did not report the immediate postoperative phosphorus values but they did report a mild increase $(0.7 \mathrm{mg} / \mathrm{dL})$ in phosphorus one month after parathyroidectomy. The late post-parathyroidectomy increase 
in phosphorus can be explained by the disappearance of the phosphaturic effect of elevated PTH and by resolution of hypercalcemia. The immediate decrease in phosphorus after parathyroidectomy in transplant patients we are reporting has no clear explanation. We can hypothesize that increased phosphorus utilization for new bone formation might be responsible for the immediate, mild post-parathyroidectomy decrease in phosphorus we found in our transplant patients.

The mean time to parathyroidectomy after renal transplant was 5.3 years. This is different from the 11 months reported by Evenepoel et al. ${ }^{7}$ This large difference might be explained by the lack of uniform indications for parathyroidectomy after renal transplantation. In our transplant group, the main indication for parathyroidectomy was persistently elevated iPTH and hypercalcemia.

We attempted to identify additional risk factors for developing severe hungry bone syndrome in ESRD patients. As presented before, the univariate analysis identified elevated pre-surgery iPTH (mean 2,042.1 ng/L), a large post-surgical iPTH decrease (mean 1,752 ng/L), young patient age (mean age 47.5 years), and elevated serum alkaline phosphatase (mean 263.95 U/L) as correlating with the occurrence of severe hungry bone syndrome. Multivariate analysis showed that young patient age and increased parathyroid gland weight are important risk factors for severe hungry bone syndrome, while elevated alkaline phosphatase showed a trend that was close to statistical significance. These factors can be used to identify patients at risk of developing severe hungry bone syndrome after parathyroidectomy in order to ensure appropriate calcium monitoring and adequate calcium replacement. The presence of the above-mentioned prognostic factors predicts a need for a longer hospital stay to ensure intravenous calcium replacement.

The study has some limitations in view of it being a retrospective chart review analysis and our population being relatively small. We tried to minimize the limitations by rigorous data collection and using pharmacy records to assess calcium repletion. We consider that our study relies largely on laboratory and pharmacy data that were appropriately captured in the medical records and increased its reliability. We identified possible predictors of severe hungry bone syndrome in ESRD patients. It is our belief that these findings should not be considered definitive but rather hypothesis-generating for prospectively designed research in the future.

\section{Conclusion}

Our study identified major differences between the clinical course and treatment after parathyroidectomy in dialysis patients versus renal transplant patients. Dialysis patients had a much higher pre-surgery iPTH and a larger post-surgery decrease in iPTH than transplant patients. Post-surgery hypocalcemia in dialysis patients was severe and required aggressive and prolonged intravenous and oral calcium replacement versus a very mild hypocalcemia requiring only brief and minimal replacement in transplant patients. Hypophosphatemia was not found during the hospital stay in the dialysis group and no patient required phosphorus repletion. The postoperative hospital stay was significantly longer in the dialysis group than in the transplant group. In dialysis patients, a young age, elevated alkaline phosphatase, elevated pre-surgery iPTH, and a large postoperative iPTH decrease might predict severe hungry bone syndrome.

\section{Author contributions}

MCF, KMMI, and PM contributed to the conception, design, analysis, and interpretation of the data; MCF contributed intellectual content of critical importance to the work described. All the authors contributed toward acquisition of data, critical revision of the manuscript and are accountable for all aspects of the work.

\section{Disclosure}

None of the authors has any disclosure to report in this work.

\section{References}

1. Salem MM. Hyperparathyroidism in the hemodialysis population: a survey of 612 patients. Am J Kidney Dis. 1997;29:862-865.

2. Melamed ML, Eustace JA, Plantinga L, et al. Changes in serum calcium, phosphate, and PTH and the risk of death in incident dialysis patients: a longitudinal study. Kidney Int. 2006;70:351-357.

3. Rodriguez M, Canalejo A, Garfia B, Aguilera E, Almaden Y. Pathogenesis of refractory secondary hyperparathyroidism. Kidney Int Suppl. 2002;80:155-160.

4. Yano S, Sugimoto T, Tsukamoto T, et al. Association of decreased calcium-sensing receptor expression with proliferation of parathyroid cells in secondary hyperparathyroidism. Kidney Int. 2000;58:1980-1986.

5. Tokumoto M, Tsuruya K, Fukuda K, Kanai H, Kuroki S, Hirakata H. Reduced p21, p27 and vitamin D receptor in the nodular hyperplasia in patients with advanced secondary hyperparathyroidism. Kidney Int. 2002;62:1196-1207.

6. Goto S, Komaba H, Fukagawa M. Pathophysiology of parathyroid hyperplasia in chronic kidney disease: preclinical and clinical basis for parathyroid intervention. NDT Plus. 2008;1 Suppl 3:iii2-iii8.

7. Evenepoel P, Claes K, Kuypers D, Maes B, Bammens B, Vanrenterghem Y. Natural history of parathyroid function and calcium metabolism after kidney transplantation: a single-centre study. Nephrol Dial Transplant. 2004;19:1281-1287.

8. Gwinner W, Suppa S, Mengelb M, et al. Early calcification of renal allografts detected by protocol biopsies: causes and clinical implications. Am J Transplant. 2005;5:1934-1941.

9. Hernandez D, Rufino M, Bartolomei S, et al. Clinical impact of preexisting vascular calcifications on mortality after renal transplantation. Kidney Int. 2005;67:2015-2020.

10. Kestenbaum B, Andress DL, Schwartz SM, et al. Survival following parathyroidectomy among United States dialysis patients. Kidney Int. 2004;66:2010-2016. 
11. Foley RN, Li S, Liu J, Gilbertson DT, Chen SC, Collins AJ. The fall and rise of parathyroidectomy in US hemodialysis patients, 1992 to 2002. J Am Soc Nephrol. 2005;16:210-218.

12. Gagné ER, Ureña P, Leite-Silva S, et al. Short and long-term efficacy of total parathyroidectomy with immediate autografting compared with subtotal parathyroidectomy in hemodialysis patients. JAm Soc Nephrol. 1992;3:1008-1017.

13. Brasier AR, Nussbaum SR. Hungry bone syndrome: clinical and biochemical predictors of its occurrence after parathyroid surgery. Am J Med. 1988;84:654-660.

14. Jofré R, López Gómez JM, Menárguez J, et al. Parathyroidectomy: whom and when? Kidney Int Suppl. 2003;85:S97-S100.

15. Dumoulin G, Hory B, Nguyen NU, et al. No trend toward a spontaneous improvement of hyperparathyroidism and high bone turnover in normocalcemic long-term renal transplant recipients. Am J Kidney Dis. 1997;29:746-753.
16. D'Alessandro AM, Melzer JS, Pirsch JD, et al. Tertiary hyperparathyroidism after renal transplantation: operative indications. Surgery. 1989;106:1049-1055.

17. Messa P, Sindici C, Cannella G, et al. Persistent secondary hyperparathyroidism after renal transplantation. Kidney Int. 1998;54: 1704-1713.

18. Torres A, Lorenzo V, Salido E. Calcium metabolism and skeletal problems after transplantation. J Am Soc Nephrol. 2002;13:551-558.

19. McCarron DA, Muther RS, Lenfesty B, Bennett WM. Parathyroid function in persistent hyperparathyroidism: relationship to gland size. Kidney Int. 1982;22:662-670.

20. Lewin E, Olgaard K. Parathyroidectomy vs calcimimetics for treatment of persistent hyperparathyroidism after kidney transplantation. Nephrol Dial Transplant. 2006;21:1766-1769.

21. Man S Oh. Acid-Base, Electrolytes. 2003. ISBN 0-9726720-0-1. Pages $341,357$.

\section{Publish your work in this journal}

The International Journal of Nephrology and Renovascular Disease is an international, peer-reviewed open-access journal focusing on the pathophysiology of the kidney and vascular supply. Epidemiology, screening, diagnosis, and treatment interventions are covered as well as basic science, biochemical and immunological studies. The journal welcomes original research, clinical studies, reviews \& evaluations, expert opinion and commentary, case reports and extended reports. The manuscript management system is completely online and includes a very quick and fair peerreview system, which is all easy to use. Visit http://www.dovepress.com/ testimonials.php to read real quotes from published authors.

Submit your manuscript here: http://www.dovepress.com/international-journal-of-nephrology-and-renovascular-disease-journal 